\title{
Efficient removal of ultrafine particles from diesel exhaust by selected tree species: implications for roadside planting for improving the quality of urban air
}

Huixia Wang 1,2, Barbara A Maher ${ }^{2 *}$ Imad AM Ahmed I Brian Davison $^{2}$

${ }^{1}$ School of Environmental and Municipal Engineering, Xi'an University of Architecture \& Technology, Xi'an, 710055, Shaanxi Province, PRC

${ }^{2}$ Lancaster Environment Centre, University of Lancaster, Lancaster, LA1 4YQ, U.K.

${ }^{3}$ Department of Earth Sciences, University of Oxford, Oxford, OX1 3AN, U.K.

*Corresponding author: $\underline{\text { b.maher@lancaster.ac.uk }}$

KEYWORDS: particulate matter (PM); human health; nanoparticles; deposition velocity;

particle removal by leaf capture; magnetic particles; transition metals 


\section{ABSTRACT}

2 Human exposure to airborne ultrafine $(<<1 \mu \mathrm{m})$ particulate pollution may pose substantial

3 hazard to human health, particularly in urban roadside environments where very large numbers

4 of people are frequently exposed to vehicle-derived ultrafine particles (UFPs). For mitigation

5 purposes, it is timely and important to quantify the deposition of traffic-derived UFPs onto

6 leaves of selected plant species, with particularly efficient particle capture (high deposition

7 velocity), and which can be installed kerbside, proximal to the emitting vehicular sources. Here,

8 we quantify the size-resolved capture efficiency of UFPs from a diesel vehicle exhaust by nine

9 temperate-zone plant species, in wind tunnel experiments. The results show that silver birch

10 (79\% UFP removal), yew (71\%) and elder (70.5\%) have very high capability for capture of

11 airborne UFPs. Metal concentrations and metal enrichment ratios in leaf leachates were also

12 highest for the post-exposure silver birch leaves; scanning electron microscopy shows UFPs

13 concentrated along the hairs of these leaves. For all but two species, magnetic measurements

14 demonstrate substantial increases in the concentration of magnetic particles deposited on the

15 leaves after exposure to the exhaust particulates. Together, these new data show that leaf-

16 deposition of UFPs is chiefly responsible for the substantial reductions in particle numbers

17 measured downwind of the vegetation. It is critical to recognise that the deposition velocity of

18 airborne particulate matter (PM) to leaves is species-specific; and often substantially higher

19 ( $\sim 10$ to 50 times higher) than the 'standard' $V_{d}$ values (e.g. $0.1-0.64 \mathrm{~cm} \mathrm{~s}^{-1}$ for $\left.P_{2.5}\right)$ used in

20 most modelling studies. The use of such low $V_{d}$ values in models results in major under-

21 estimation of PM removal by roadside vegetation, and thus misrepresents the efficacy of 
selected vegetation species for substantial (>> 20\%) removal of PM. Given the potential hazard

to health posed by UFPs, and the removal efficiencies shown here (and by previous roadside measurements), roadside planting at PM 'hotspots' of selected species (maintained at or below head height) can contribute substantially and quickly to improvement in urban air quality, and reductions in human exposure. These findings can contribute to development and implementation of mitigation policies of traffic-derived PM on an international scale.

\section{Introduction}

\subsection{Airborne particulate matter, and ultrafine particles}

Airborne particulate matter (PM) is a health hazard on a global scale. Ultrafine particles (UFPs, aerodynamic diameter $<1000 \mathrm{~nm}$ ), with a lifetime in the atmosphere ranging from a few seconds to several days, may pose particular risk to the health of the very large populations living, commuting and working in polluted urban environments, especially near major roadways $^{1}$. UFPs have been shown to penetrate the respiratory system, enter the blood circulation, transfer to extra-pulmonary organs $\mathrm{s}^{2-3}$, and may also enter the brain directly via the olfactory bulb ${ }^{4-5}$. UFPs may be more toxic than microscale particles with the same chemical composition and at the same mass concentration owing to their very large surface area, increased chemical reactivity and ease of cell penetration ${ }^{6-9}$.

Airborne UFPs can be derived both from anthropogenic and natural sources (e.g. biomass burning), but in many urban centres, motor vehicles are the primary emission sources of UFPs to the atmosphere, particularly in the morning and afternoon/evening rush hours ${ }^{10-12}$. Primary, vehicle-derived UFPs are produced directly from fuel combustion ${ }^{13-14}$, engine wear ${ }^{15}$ and from 
45 frictional processes, especially brake wear ${ }^{16-17}$. Re-suspension of road dust provides multiple 46 opportunities for post-emission supply of airborne UFPs ${ }^{18}$. Primary, vehicle-derived UFPs are 47 often enriched in highly bioreactive transition metal species, especially $\mathrm{Fe}\left(\right.$ both $\mathrm{Fe}^{2+}$ and $\mathrm{Fe}^{3+}$ ), $48 \mathrm{Cu}, \mathrm{Mn}$ and $\mathrm{Cr}^{12,19}$, and other metals including $\mathrm{Zn}, \mathrm{Ni}, \mathrm{V}$, and $\mathrm{Pb}^{12,20}$. Secondary UFPs form 49 in the atmosphere through photochemical reactions involving gaseous precursors and post50 emission nucleation and condensation processes ${ }^{10,21}$.

51 Currently, policies for regulation of airborne PM are based on mass concentrations, of $52 \mathrm{PM}_{10}$ and/or $\mathrm{PM}_{2.5}$ (of aerodynamic diameter $<10 \mu \mathrm{m}$ or $<2.5 \mu \mathrm{m}$, respectively). The contribution of UFPs to such mass-based metrics is minimal $(<10 \%)$, whereas they make up $54 \sim 80 \%$ or more of the PM number ${ }^{14,21-22}$.

Most of the PM emitted from vehicle exhausts lies within the $\mathrm{PM}_{1.0}$ size range, with median 56 mass diameter between $\sim 100$ and $200 \mathrm{~nm}$ and a median number diameter of $\sim 20 \mathrm{~nm}^{23-24}$.

57 Emissions control strategies, based on engine design and after-treatment devices, have reduced 58 the average mass of particle emissions, but had limited success in reducing UFP numbers. 59 Indeed, some studies have reported increased UFP numbers ${ }^{25}$ and increased UFP toxicity ${ }^{26-27}$ 60 with the introduction of after-treatment devices. Hence, it is timely and important to identify 61 feasible and efficient technologies that can capture airborne UFPs, thus reducing human 62 exposure and damage to health.

63 
66 deposition on leaves, but also to increase PM concentrations, by impeding airflow and reducing

67 the dispersion of PM. As noted by recent reports ${ }^{28}$, and reviews ${ }^{29}$, many modelling-based

68 studies (using computational fluid dynamics, CFD, to simulate PM emission, dispersion and

69 deposition) have indicated rather small reductions, i.e. a few percent, in $\mathrm{PM}_{10}$ or $\mathrm{PM}_{2.5}$

70 concentrations by deposition onto roadside vegetation ${ }^{30-33}$. If robust, such model-derived

71 outcomes indicate that roadside planting schemes are unlikely to produce any large reductions

72 ('> 20\%') in $\mathrm{PM}_{10}$ or $\mathrm{PM}_{2.5}$ concentrations. Indeed, $\mathrm{AQEG}^{28}$ warns against 'campaigning zeal'

73 in 'popular publications' in communicating the likely improvements in air quality achievable

74 with roadside vegetation.

75 In a recent review ${ }^{34}$ of some measurement-based (roadside, and wind tunnel) studies, the

76 reported removal efficiencies of PM concentrations by roadside vegetation vary enormously,

77 from enhancement of $\mathrm{PM}_{2.5}$ (by up to 95\%) to reductions (in, variably, PM, total suspended

78 particulates, UFPs, $\mathrm{PM}_{1}, \mathrm{PM}_{2.5}, \mathrm{PM}_{10}$ ) of $\sim 2$ to $90 \%$.

79 A fundamental factor appears to be key to both the parsimony of the model estimates and

80 diversity of the measured PM removal rates. That factor is the (mis)treatment of particle

81 deposition velocity $\left(V_{\mathrm{d}}\right)$ to leaf surfaces. Notwithstanding that particle deposition rates depend

82 on a range of factors, including particle diameter, PM concentration and wind speed, the critical

83 influence of species-specific leaf surface properties on controlling particle deposition rates,

84 capture, and agglomeration appears to have been under-recognised in measurement-based 
studies, and substantially under-parameterised (i.e. typically by 5 to 50 times), in the majority of CFD models ${ }^{12,35}$.

Leaf number, size, surface structures and the thickness, structure and composition of epicuticular wax play critical roles in determining $V_{\mathrm{d}}$ and particle retention ${ }^{36-40}$. For example, using magnetic particle loadings as a proxy for $\mathrm{PM} 10$, Mitchell et al. ${ }^{39}$ reported (magnetic) $V_{\mathrm{d}}$ values varying for different plant species as a function of leaf micro-topography, especially hairiness and rugosity. Lowest $V_{\mathrm{d}}$ values ranged from 0.5 to $0.9 \mathrm{~cm} \mathrm{~s}^{-1}$ for sweet chestnut, elder, elm and willow; intermediate values from 1.3 to $1.9 \mathrm{~cm} \mathrm{~s}^{-1}$ for sycamore, horse chestnut, ash and maple; higher $V_{\mathrm{d}}$ values, from 2.4 to $4.6 \mathrm{~cm} \mathrm{~s}^{-1}$, for lime, beech and silver birch. Deposition velocities of $10 \mathrm{~cm} \mathrm{~s}^{-1}$ have been reported for grassland ${ }^{41}$ and Douglas fir for $\mathrm{PM}_{10}{ }^{42}$ while Freer-Smith et al. ${ }^{43}$ have reported $V_{\mathrm{d}}$ values exceeding $30 \mathrm{~cm} \mathrm{~s}^{-1}$ for maple, pine and cypress 96 for $\mathrm{PM}_{1.0}$.

In contrast, and critically, many modelling-based studies choose to use 'standard' deposition velocity values as low as $0.64 \mathrm{~cm} \mathrm{~s}^{-1}$ or $0.1 \mathrm{~cm} \mathrm{~s}^{-1}$ for $\mathrm{PM}_{2.5}{ }^{30,44-45}$, or $0.2 \mathrm{~cm} \mathrm{~s}^{-1}$

99 for $\mathrm{PM}_{10}{ }^{33}$. Such values seem both low and indiscriminate, despite available data showing the

100 species-specific nature of this key term. It is therefore unsurprising (and indeed self-fulfilling)

101 that such modelling studies typically identify dominance of the aerodynamic (reduced 102 ventilation) over the depositional effects of roadside vegetation.

103 Based on the measured deposition velocities, then installation, close to the emitting vehicle 104 sources, of selected species with optimal $V_{\mathrm{d}}$ values, and controlled height and permeability, can 
substantially reduce concentrations of traffic-derived PM (Fig. S1), whether at the roadside ${ }^{46}$

106 or in adjacent indoor environments.

107 For example, for a $V_{\mathrm{d}}$ of $4.6 \mathrm{~cm} \mathrm{~s}^{-1}$ (e.g. silver birch), and leaf surface area of $125 \mathrm{~m}^{2} /$ tree

108 (canopy diameter $8 \mathrm{~m}$ ), 8 trees/100 m street length would remove $50 \%$ of the traffic-derived

109 PM10 (Fig. S1). Such removal rates tally with published studies. In a street canyon setting, leaf

110 capture of PM by young, roadside silver birch trees was associated with major reductions (60

$111-80 \%)$ in adjacent indoor concentrations of $\mathrm{PM}_{1.0}, \mathrm{PM}_{2.5}$ and $\mathrm{PM}_{10}{ }^{12}$.

112 The orientation of roads in relation to predominant wind directions must also, of course,

113 be taken into account, to ensure effective design of any newly-installed vegetation whether at

114 the roadside, or within the roadway (e.g. as central lines, or lane separators).

115 Not only species selection but management is important since tall trees (> rooftop height)

116 and high canopy density ${ }^{47}$ can increase airborne PM mass concentrations, especially in street

117 canyons, by obstructing airflow and reducing PM dispersion, effectively trapping the

118 pollutants $^{33}$. Additionally, some plant species can act as sources of biogenic volatile organic

119 compounds (VOCs) to the urban atmosphere. For example, oxidation of isoprene,

120 monotrepenes and sesquiterpenes can enhance secondary formation of $\mathrm{PM}_{2.5}$ and of ground

121 level ozone ${ }^{48-50}$. Albeit less hazardous than UFPs, the pollen of some species can trigger

122 allergic rhinitis (hay fever).

123 For humid areas like Lancaster, the PM capture capability of birch leaves is renewed

124 through PM wash-off by abundant rainfall ${ }^{39,51}$. In drier areas, watering schemes might enable 
optimized PM removal by vegetation. The potential for contamination of the roadside soil ${ }^{52}$

126 might require management, depending on the number of years of planned exposure time.

127 Depending on climate (especially humidity, rainfall), some species are likely to offer

128 permanent take-up of PM via particle entry through the leaf stomata, especially in the case of

129 waxy, evergreen leaves. Hence, combining tested, efficient, deciduous and evergreen species

130 might optimize PM removal through the entire year.

131 In terms of management, the selected roadside vegetation barrier, comprising selected,

132 high-deposition-velocity, PM-tolerant mixed evergreen and deciduous species, should be kept

133 well below roof height ${ }^{35}$, and pruned to prevent development of a dense canopy crown, in order

134 to facilitate atmospheric dispersion of PM. Selected species of trees, managed as hedges

135 ('tredges' $($ )), may thus provide the best option for immediate improvement of air quality,

136 especially in PM 'hotspots', wherever the most, and the most vulnerable people (e.g. young

137 children) receive the greatest PM exposure.

$138 \quad 1.3$ Vegetation impacts on UFPs

139 Despite their abundance in the urban atmosphere and their potential toxicity, UFP removal

140 by plants has so far received relatively little attention. Field measurements to quantify the

141 influence of urban plants on UFPs and particle number concentrations (PNCs) are few. In

142 Raleigh, Carolina, Baldauf et al. ${ }^{53}$ found PNCs reductions of $15-50 \%$ at distances up to $10 \mathrm{~s}$

143 of metres behind a (discontinuous) noise barrier; combined noise and vegetation barriers

144 consistently reduced the PNCs more efficiently than noise barriers alone. 
in PNCs by a coniferous vegetation barrier, during intervals with cross-road wind directions.

147 Lin et al. ${ }^{55}$ reported 38 to $64 \%$ reduction in UFPs (14 to $102 \mathrm{~nm}$ ) concentrations behind a

148 deciduous roadside vegetation barrier when in leaf, but no reduction in winter without

149 foliage.

150 Fewer studies have examined the effects of different types of vegetation on reducing UFP

151 numbers. Using pine and juniper branches in a wind tunnel, Lin and Khlystov ${ }^{56}$ found UFP

152 removal efficiency to be directly proportional to the vegetation packing density, and inversely

153 proportional to particle size and wind speed. Freer-Smith et al. ${ }^{43}$ found that $V_{\mathrm{d}}$ values were

154 dependent on plant species, particle size and ambient PM concentrations. For some coniferous species, they reported $V_{\mathrm{d}}$ values for UFPs as high as 25 to $36 \mathrm{~cm} \mathrm{~s}^{-1}$ at a busy road, and 12 to

$15630 \mathrm{~cm} \mathrm{~s}^{-1}$ at a parkland site. Hwang et al. ${ }^{57}$ studied five different vegetation types in a deposition

157 chamber. They reported higher $V_{\mathrm{d}}$ for UFPs for needle leaf compared with broadleaf trees; the

158 leaf surface roughness also influenced the deposition efficiency.

159 In summary, a limited number of studies has examined the removal efficiency of traffic-

160 produced UFPs by different plant species. Given limited space in urban areas, it is important

161 that the most effective plant species for UFP removal should be selected for urban greening.

162 Here, we examine, in a wind tunnel, the size-resolved removal of UFPs by nine plant species:

163 silver birch (Betula pendula), yew (Taxus baccata), nettle (Urtica fissa), beech (Fagus

164 sylvatica), cherry (Prunus avium), elder (Sambucus nigra), maple (Acer campestre), hawthorn

165 (Crataegus monogyna) and ash (Fraxinus excelsior). Our new data indicate that selected plant 
166 species can remove by surface deposition substantial amounts ( $>50 \%)$ of ultrafine exhaust-

167 derived PM, and of the heavy metals contained within the high particle number concentrations

168 of this PM fraction. Fast, non-destructive magnetic measurements provide an effective

169 indicator of leaf particle deposition. Scanning electron microscopy can identify the major leaf

170 micro-sites associated with greatest particle accumulation. Hence, roadside planting of

171 carefully-selected and managed plant species can effectively mitigate exposure of road users

172 and adjacent residents (especially vulnerable groups like school children) to UFP pollution near

173 major roads. Careful testing and selection of the most efficient species can readily improve air

174 quality.

175

176 2. Experimental methods

$177 \quad 2.1$ Plant Species

178 UFP removal efficiency was measured in a rectangular wind tunnel $(200 \mathrm{~cm}$ long, $75 \mathrm{~cm}$

179 wide, $75 \mathrm{~cm}$ high, Fig. S2). Nine plant species with different leaf surface characteristics and

180 particle deposition velocities were selected based on our previous study ${ }^{39}$, including silver

181 birch, yew, nettle, beech, cherry, elder, maple, hawthorn and ash. These species are widespread

182 in temperate regions, have different leaf retention behavior (i.e., deciduous vs evergreen

183 species) and different leaf morphologies (i.e., broad leaves vs needles) and micro-topographies,

184 which are expected to have an influence on UFP deposition and accumulation (Table S1,

185 Supporting Information). 
187 University campus (maple, ash, hawthorn, beech, cherry, elder) and Williamson Park,

188 Lancaster (yew, silver birch, nettle), as far as possible from roads. Branches $(\sim 60 \mathrm{~cm}$ in

189 length) of each species, freshly cut on the day of the measurements, were supported vertically

190 and uniformly as a vegetation block (i.e. with very similar leaf area index, LAI, values, Table

191 S1) to ensure that most of the air stream passes through them (Fig. S2, Supporting

192 Information). Particles were emitted from the exhaust of an idling diesel engine (2.1 litre,

193 with catalytic converter; BS EN590 Standard diesel fuel), and injected via smooth plastic

194 tubing into the wind tunnel. A fan positioned at the centre of the front sidewall was used to

195 produce steady airflow, of $1.0 \mathrm{~m} \mathrm{~s}^{-1}$ (typical for the Lancaster area in summer ${ }^{58}$, and to mix

196 the exhaust stream with the airflow.

197

198

\subsection{Particle number concentrations and size distributions}

199 A GRIMM model 5.400 scanning mobility particle sizer (SMPS), comprising a long

200 differential mobility analyser (DMA, model 5.5-900), was used to measure particles in 44 size

201 categories, between 9.8 and $874.8 \mathrm{~nm}$, to obtain the size distribution and count PNCs over

202 consecutive 7 min intervals. Particle sampling was carried out via plastic tubing $(\sim 60 \mathrm{~cm})$

203 connected first to a sampling port located upwind $(\sim 20 \mathrm{~cm})$ and then downwind $(\sim 20 \mathrm{~cm})$ of

204 the vegetation, to sample continuous PNCs and particle size distributions. PNCs and size

205 distribution measurements were first made in the absence of any vegetation for four separate 7

206 min. intervals. Measurements were then made first, upwind and then, downwind of the different 
207 vegetation species, over successive sampling durations; $5 \times 7$ mins for each plant species. For 208 each of the plant species, the collection efficiency was measured at a wind speed of $1.0 \mathrm{~m} \mathrm{~s}^{-1}$,

209 typical in summer in the study area (Lancaster, U.K.).

210 At the end of the experiment, $\sim 5 \%$ of the total leaves from each vegetation block was

211 weighed (Oertling KC22 microbalance) then scanned, and leaf area measured through counting

212 image pixels. Total foliage area was determined by the mass proportion of the scanned leaf

213 weight to total weight and leaf area; the total leaf area was divided by the crown area to

214 determine the LAI, to ensure comparability between the species removal efficiencies (the LAI

215 values varied very little, from 7.2 to 8.8 , Table $S 1)$.

216 Leaf samples of each species were collected before exposure to the diesel exhaust (here

217 labelled as 0 minutes) and then after successive exposure intervals (i.e. after 2, 5, 10, 20, 30,

218 and 35 minutes), using gloves to avoid contamination. The leaves were stored (upper surface

219 to upper surface) in ziplock bags, at $4{ }^{\circ} \mathrm{C}$, prior to scanning (5-6 leaves per individual species

220 sample), and then packed into $10 \mathrm{~cm}^{3}$ plastic pots for magnetic measurements (at the Centre

221 for Environmental Magnetism and Palaeomagnetism, Lancaster University).

\subsection{Magnetic measurements}

Measurements were made of anhysteretic remanent magnetization (ARM) and the

saturation remanence (SIRM) of the leaves pre- and post-exposure (see Supporting

226 Information). ARM is sensitive to the presence of ferrimagnetic particles with a mean particle

227 size of $\sim 25 \mathrm{~nm}^{59}$. The SIRM indicates the total concentration of magnetic particles on the pre- 
and post-exposure leaves. ARM was induced using a Molspin A. F. demagnetiser, with ARM attachment, generating a dc biasing field $(0.08 \mathrm{mT})$ in the presence of an alternating field (100 milliTesla (mT) peak field). The ARM was measured using a spinner magnetometer (JR-6A,

231 AGICO). The susceptibility of ARM ( $\chi$ ARM) was calculated by normalizing the ARM by the dc 232 biasing field. fields of 100 and $300 \mathrm{mT}$ ) using a Molspin pulse magnetizer. Calibration of the magnetometer was performed, on a regular basis, using a cross-calibrated rock sample $\left(56.05 \times 10^{-8} \mathrm{Am}^{2}\right)$. All samples were measured in triplicate; the average value of each magnetic parameter was normalised for the leaf surface area (in $\mathrm{m}^{2}$ ).

\subsection{Metals analysis}

The leaf-deposited PM was also evaluated by an acid wash procedure and analysis of

241 metal concentrations using inductively coupled plasma-mass spectrometry (ICP-MS). Two

242 leaves from each species, pre- and post-exposure, were washed thoroughly using purified 2\%

$243 \mathrm{HNO}_{3}$ (the background metals concentration in $2 \% \mathrm{HNO}_{3}$ shown in Fig. S3) into acid-

244 cleaned centrifuge tubes. The resultant, replicate leachates were then analysed for $\mathrm{Mn}, \mathrm{Fe}$,

$245 \mathrm{Co}, \mathrm{Ni}, \mathrm{Cu}, \mathrm{Zn}, \mathrm{Ti}, \mathrm{V}, \mathrm{Cr}, \mathrm{As}, \mathrm{Zr}, \mathrm{Mo}, \mathrm{Se}, \mathrm{Cd}, \mathrm{Sn}, \mathrm{Sb}, \mathrm{Pt}$ and $\mathrm{Pb}$ using a Perkin Elmer

246 quadrupole NexION 350D ICP-MS instrument. The metal concentrations reported here

247 represent the average concentrations. The elements $\mathrm{Se}, \mathrm{Cd}, \mathrm{Sn}, \mathrm{Sb}, \mathrm{Pt}$ and $\mathrm{Pb}$ were measured

248 under non-pressurised conditions (standard mode) whereas the remaining elements were 
measured in a collision cell with kinetic energy discrimination (collision mode) using helium gas. Metal compositions in the stock acid wash solution were well below $25 \mathrm{ng} \mathrm{L}^{-1}$, except for

$251 \mathrm{Ti}\left(<65 \mathrm{ng} \mathrm{L}^{-1}\right)$ and $\mathrm{Zn}\left(<201 \mathrm{ng} \mathrm{L}^{-1}\right)$, most likely a contribution from tubing used during the ICP-MS analysis.

\subsection{Electron Microscopy}

To identify UFP capture sites, leaves of the most effective species (silver birch) were examined using scanning electron microscopy (SEM) and energy dispersive spectroscopy (EDAX). Three leaf discs (10 mm diameter) of the pre- and post-exposure silver birch leaves were cut with a clean ceramic blade and coated with a thin layer $(<5 \mathrm{~nm})$ of gold using an ion sputter. Each leaf disc was degassed (for $3 \mathrm{~h}$ at 0.7 bar), mounted on an aluminium stub over double-sided sticky tape and their microstructure examined with an SEM (FEI Quanta 650, FEI, Hillsboro, Oregon, USA) operating at an accelerating voltage of 10 or $20 \mathrm{kV}$. were collected after acquisition times of up to $5 \mathrm{~min}$. At least 5 spots from each leaf (before and after exposure) were analysed by EDAX.

$$
\mathrm{R}_{\mathrm{eff}(\mathrm{i})}(\%)=\frac{\mathrm{PNC}_{\text {upwind(i)- }} \mathrm{PNC}_{\text {downwind(i) }}}{\mathrm{PNC}_{\text {upwind(i) }}} \times 100
$$


272 where $\mathrm{R}_{\mathrm{eff}}(\%)$ is the removal efficiency, $\mathrm{PNC}_{\text {upwind }}$ is the particle number concentration

273 upwind in the wind tunnel experiment $\left(\# / \mathrm{cm}^{3}\right), \mathrm{PNC}_{\text {downwind }}$ is the PNC downwind $\left(\# / \mathrm{cm}^{3}\right)$,

274 and $\mathrm{i}$ is the different particle size bins (i.e., $9.8-874.8 \mathrm{~nm}, 9.8-30 \mathrm{~nm}, 30-100 \mathrm{~nm}, 100-300 \mathrm{~nm}$

275 and 300-874.8 $\mathrm{nm})$.

276 The Kolmogorov-Smirnov and Levene tests were used to verify the assumption of

277 normality and the homogeneity of variances for the magnetic data (ARM, IRM100, IRM 300

278 and SIRM) and metal concentrations. One way analysis of variances (ANOVA) was carried

279 out to investigate the effects of the plant species, and time intervals on the magnetic data. The

280 significance of differences among the plant species were checked with Tukey's test $(p=$

281 0.05). The differences in metal concentrations among plant species were also tested by

282 ANOVA and Tukey's test. Differences in metal concentrations between pre- and post-

283 exposure leaves were tested using student's $t$ test for each species. The data were analysed

284 with SPSS software (ver. 20.0, IBM Corp, Armonk, NY).

285

286

287 3. Results and discussion

2883.1 UFP removal efficiency of different plant species

289 The measured mean PNC for the diesel exhaust (in the absence of vegetation) was

$290 \sim 25 \times 10^{5} / \mathrm{cm}^{3}$ (Fig. 1). There is no obvious increase in PNC upwind of the tested vegetation

291 species compared with the no-vegetation case (Fig. S3, Supporting Information); 
292 occasionally, the upwind PNCs are slightly lower, perhaps indicating some upward deflection 293 of UFPs away from the central CPC measurement point.
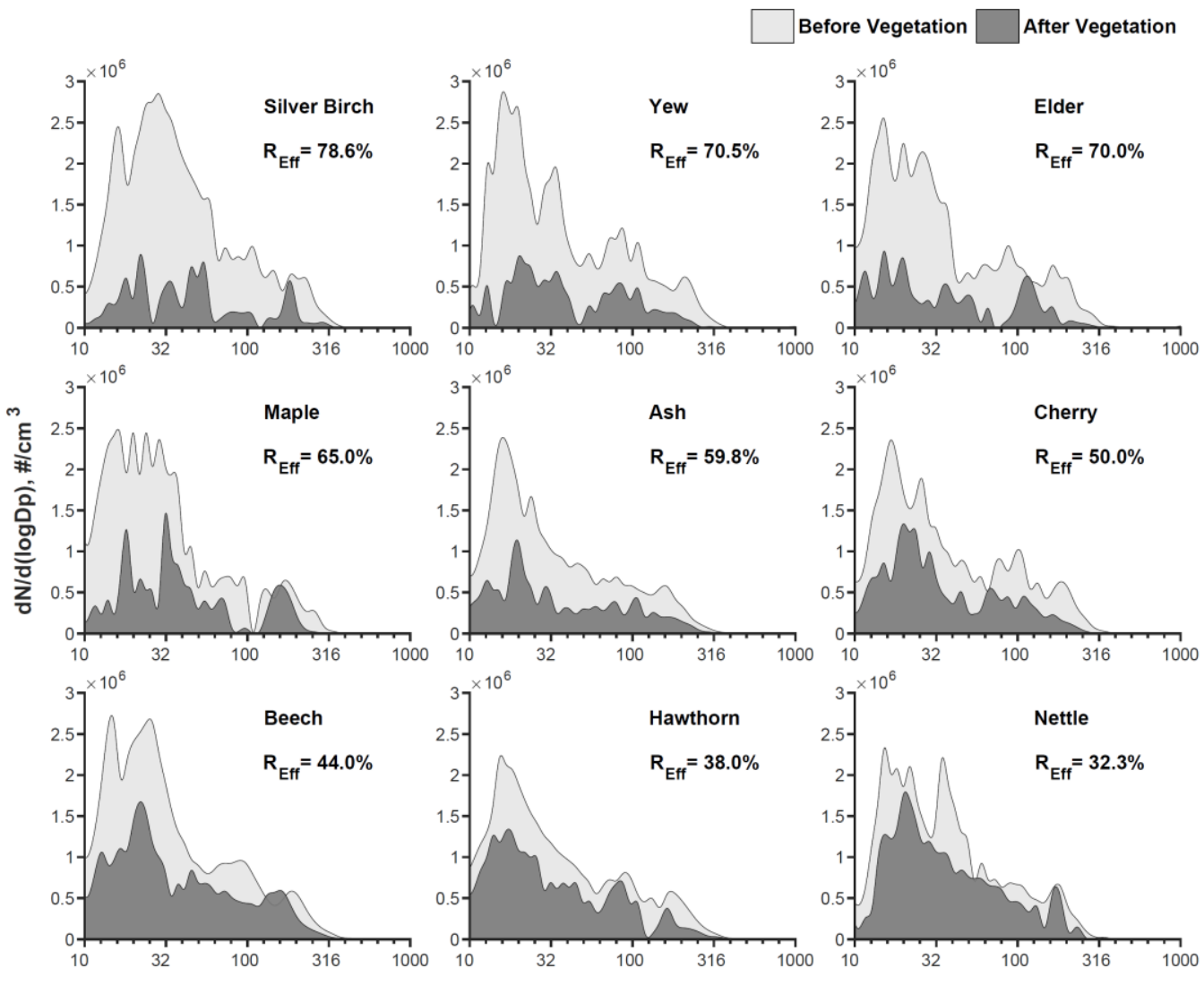

Particle size $(\mathrm{nm})$

296 Fig. 1. Mean particle number distribution pre- and post-exposure (35 mins) of each

297 vegetation species to the diesel exhaust ('Before Vegetation' = upwind of vegetation block; 'After Vegetation' = downwind of vegetation block). REff (\%) indicate the removal efficiency of UFPs by each species.

The average number size distributions of the UFPs, both in the absence of, and upwind and downwind from the vegetation displayed two major peaks, at 16 and $26 \mathrm{~nm}$ (nucleation mode), and a subsidiary peak of accumulation mode (soot) particles at $\sim 100 \mathrm{~nm}$ (Figs. 1 and 
304 S3). This distribution showed little change upwind and downwind for most of the plant species

305 investigated, indicating the permeability of each tested vegetation block to the air stream. In

306 marked contrast, measurements of $\mathrm{PM}_{2.5}$ (by TSI, USA, SidePak AM520) upwind and

307 downwind of a dense conifer species (juniper) identifies 'blocking' of air flow and resultant

308 upwind enhancement of PNCs (Fig. S4). Some species induced slight increases in downwind

309 mean particle size (see below).

310 Compared to the no-vegetation measurement, significant PNC reduction was measured

311 downwind of most species tested, with much of the reduction occurring for the smaller particle

312 sizes. Different plant species resulted in different removal efficiencies, reducing PNCs by up

313 to $\sim 79 \%$. Silver birch is the most efficient species in removing UFPs, followed by yew $>$ elder

$314>$ maple $>$ ash $>$ cherry $>$ beech $>$ hawthorn $>$ nettle (Fig. 1).

315 When the diesel exhaust had passed through the vegetation, the geomean diameter showed

316 small but measurable increases, except in the case of hawthorn, elder and cherry (Table S3,

317 Supporting Information). Silver birch and yew showed the largest mean increase in particle

318 size, from 20.8 to $27.2 \mathrm{~nm}$, and 19.3 to $29.6 \mathrm{~nm}$, respectively, followed by maple (from 18.5 to

$31923.8 \mathrm{~nm})$.

320 Dividing the PNC data into four size bins, $9.8-30 \mathrm{~nm}\left(\mathrm{~N}_{9.8}-30\right.$; nucleation mode), 30-100

$321 \mathrm{~nm}\left(\mathrm{~N}_{30-100}\right.$; Aitken mode), 100-300 nm ( $\mathrm{N}_{100-300}$; accumulation mode) and 300-874.8 $\mathrm{nm}$

322 (N9.8-30; coarse mode), the plants displayed differences in their removal of different particle

323 size ranges (Fig. 2). For the nucleation mode $(9.8-30 \mathrm{~nm})$, silver birch removed the greatest

324 particle numbers, followed by yew $>$ elder $>$ maple $>$ cherry $>$ ash $>$ hawthorn $>$ nettle. The 
325 nine different plant species followed this same order of removal efficiency for the PNCs in

326 the accumulation and coarse modes.

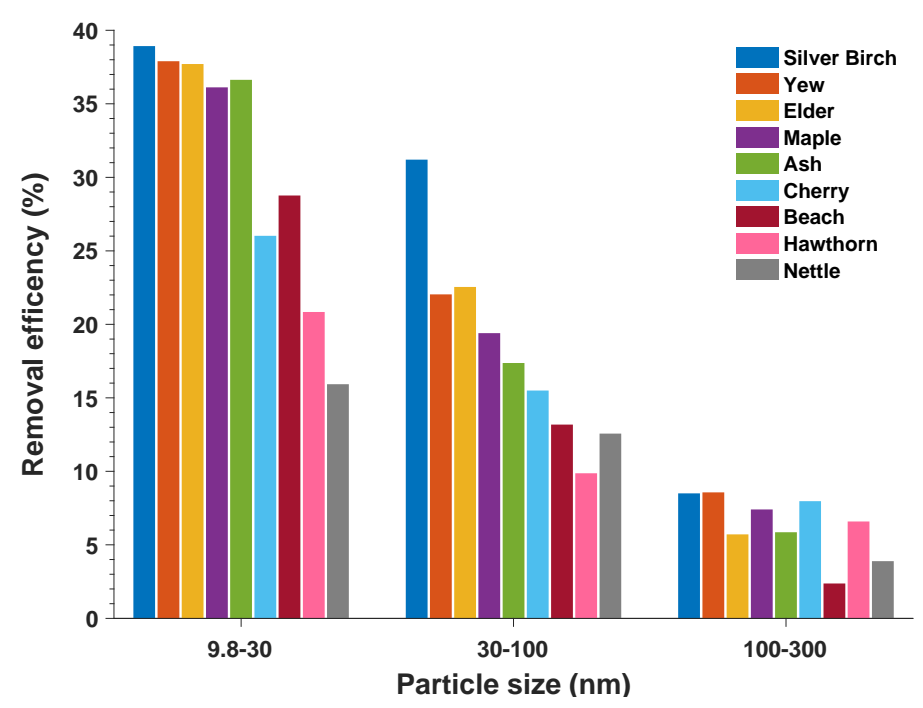

328 Fig. 2. The UFP removal efficiency of different plant species for different particle size bins.

3.2 Leaf magnetic values, magnetic mineralogy and grain sizes. 



342 Figure 3. (A) Pre- and (B) post-exposure leaves display differences in magnetic particle

343 loadings, as measured by ARM, IRM100, IRM300 and IRM1000

347 leaves showed both the highest rate and most continuous accumulation of magnetic particles

348 through the whole exposure period, followed by yew and elder, and then maple and nettle (Fig.

349 S5, Supporting Information). Hawthorn showed little magnetic difference between preexperiment and post-exposure leaves (Fig. S5B). Elder, maple, ash, cherry, beech and nettle all appear to reach a dynamic equilibrium (i.e. particle deposition balanced by particle resuspension) in magnetic particle loadings within the timespan of the experimental exposure. 
All leaves acquired most magnetic remanence at low applied fields; 70\% by $100 \mathrm{mT}$, magnetically "soft" material (i.e., easily magnetized and demagnetized), such as magnetite $\mathrm{mT}$ ), indicating the presence of some maghemite and/or some nanoparticulate haematite ${ }^{60}$. The acquisition of some additional remanence (mostly $\sim 1$ to $2 \%$, max $8 \%$ ) at highest dc fields (> $300 \mathrm{mT}$ ) shows that magnetically 'hard' haematite also contributes to the leaf magnetic mineralogy. Given that haematite is much more weakly magnetic than magnetite, then up to $\sim 40$ times more haematite than magnetite may have deposited on the leaves during exposure to the diesel exhaust stream.

The different plant species also showed different leaf $\chi_{\text {ARM }} /$ SIRM values after exposure to the exhaust. Silver birch leaves had the highest $\chi_{\text {ARM }} /$ SIRM values, ranging from 62 to 138 $\times 10^{-5} \mathrm{~A}^{-1}$, with successive increases with exposure time. Because ARM is particularly sensitive to the presence of ultrafine magnetite particles, around $30 \mathrm{~nm}$ in $\operatorname{size}^{59}, \chi_{\mathrm{ARM}} / \mathrm{IRM}_{300}$ values can

367 be used as a rough estimate of magnetite grain size.

The magnetic particles present on the pre-exposure silver birch leaves were in the size range of $\leq 100 \mathrm{~nm}$ (Fig. S6, Supporting Information). After 20 minutes' exposure to the diesel

370 exhaust, the magnetic grain size of the particles deposited on the silver birch leaves decreased 371 to $\sim 20 \mathrm{~nm}$ in size. When the exposure time increased from 20 to $35 \mathrm{mins}$, the magnetic particle 372 size increased to $\sim 70 \mathrm{~nm}$. In contrast, the size of the magnetic particles on nettle leaves was in 373 the range of $\sim 200-600 \mathrm{~nm}$ (Fig. S6, Supporting Information). 
375 3.3 Metal concentrations of leaf-deposited PM

376 The concentrations of $\mathrm{Mn}, \mathrm{Fe}, \mathrm{Cu}$ and $\mathrm{Zn}$ on the post-exposure leaves were much higher

377 than the other metals analyzed (Fig. 4). The metal contributions, post-exposure, are as

378 follows: $\mathrm{Mn}>\mathrm{Zn}>\mathrm{Fe}>\mathrm{Cu}>\mathrm{Ni}>\mathrm{Ti}>\mathrm{Cr}>\mathrm{Pb}>\mathrm{As}>\mathrm{Se}>\mathrm{Cd}>\mathrm{V}>\mathrm{Co}>\mathrm{Zr}>\mathrm{Mo}>\mathrm{Pt}$.

379 The very high Mn concentrations probably arise from the use of the diesel fuel additive,

380 methylcyclopentadienyl manganese tricarbonyl (MMT) and/or from engine, especially

381 cylinder, wear. The latter source, together with lubricating oil, is also likely to contribute the

382 observed concentrations of $\mathrm{Zn}, \mathrm{Fe}, \mathrm{Cu}$, and $\mathrm{Cr}^{13}$. The post-exposure metal concentrations

383 from the leaf-deposited PM differed significantly between plant species

384 (Fig. 4 and Table S4, Supporting Information). The highest metal concentrations were found 385 in the leaf leachates from the silver birch, followed by yew and maple. 


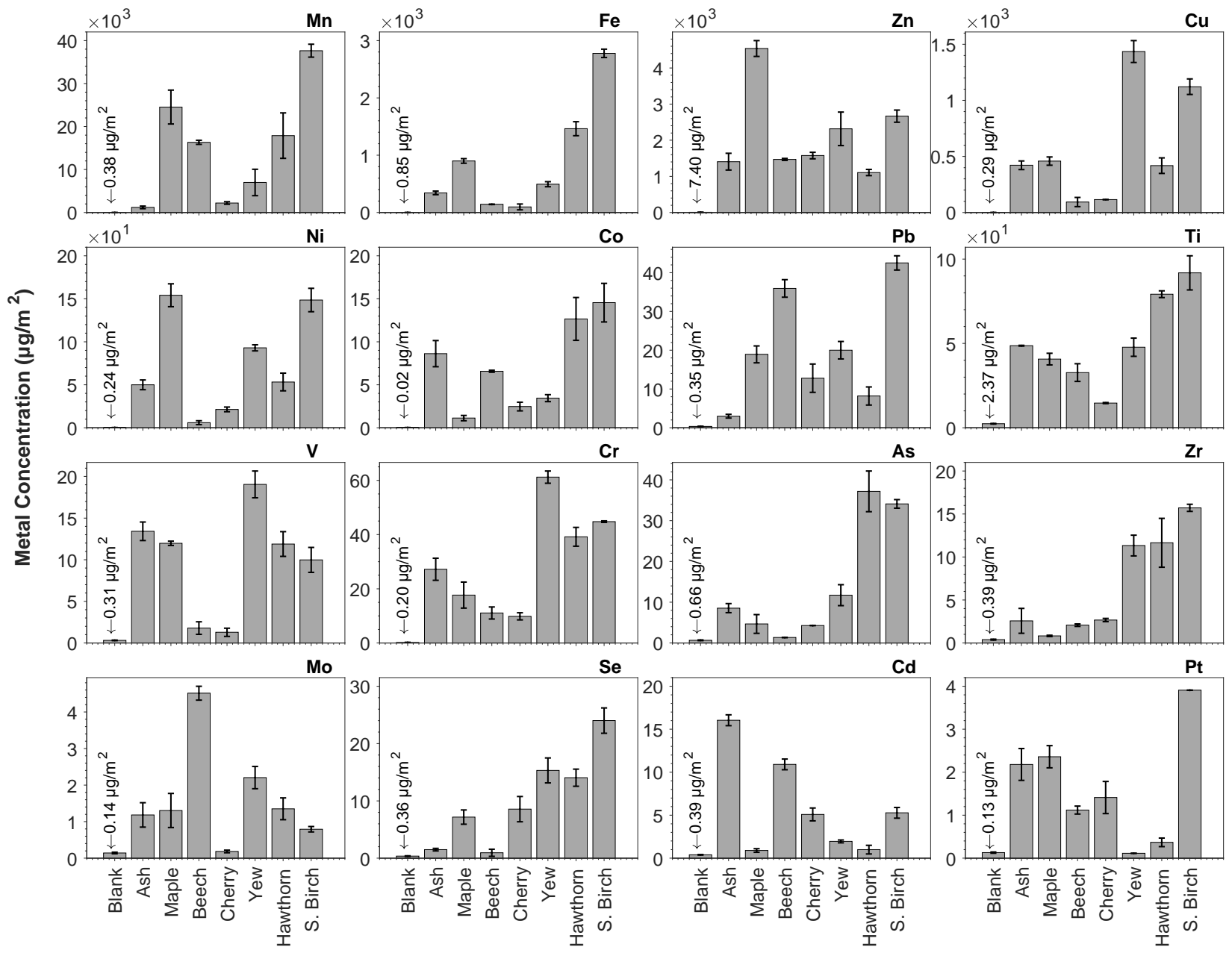

388 Fig. 4 Metal concentrations of leaf leachates post-exposure (i.e. metal concentrationspost-exposure

$389-$ metal concentrationspre-exposure). ICP-MS data expressed as $\mu \mathrm{g}$ metal per $\mathrm{m}^{2}$ of leaf surface

area.

\subsection{SEM-EDX}

Scanning electron micrographs (Figs. 5 and 6) show the typical rough, hairy morphology

of the adaxial leaf surfaces of the most efficient species, silver birch, which is hypostomatic 


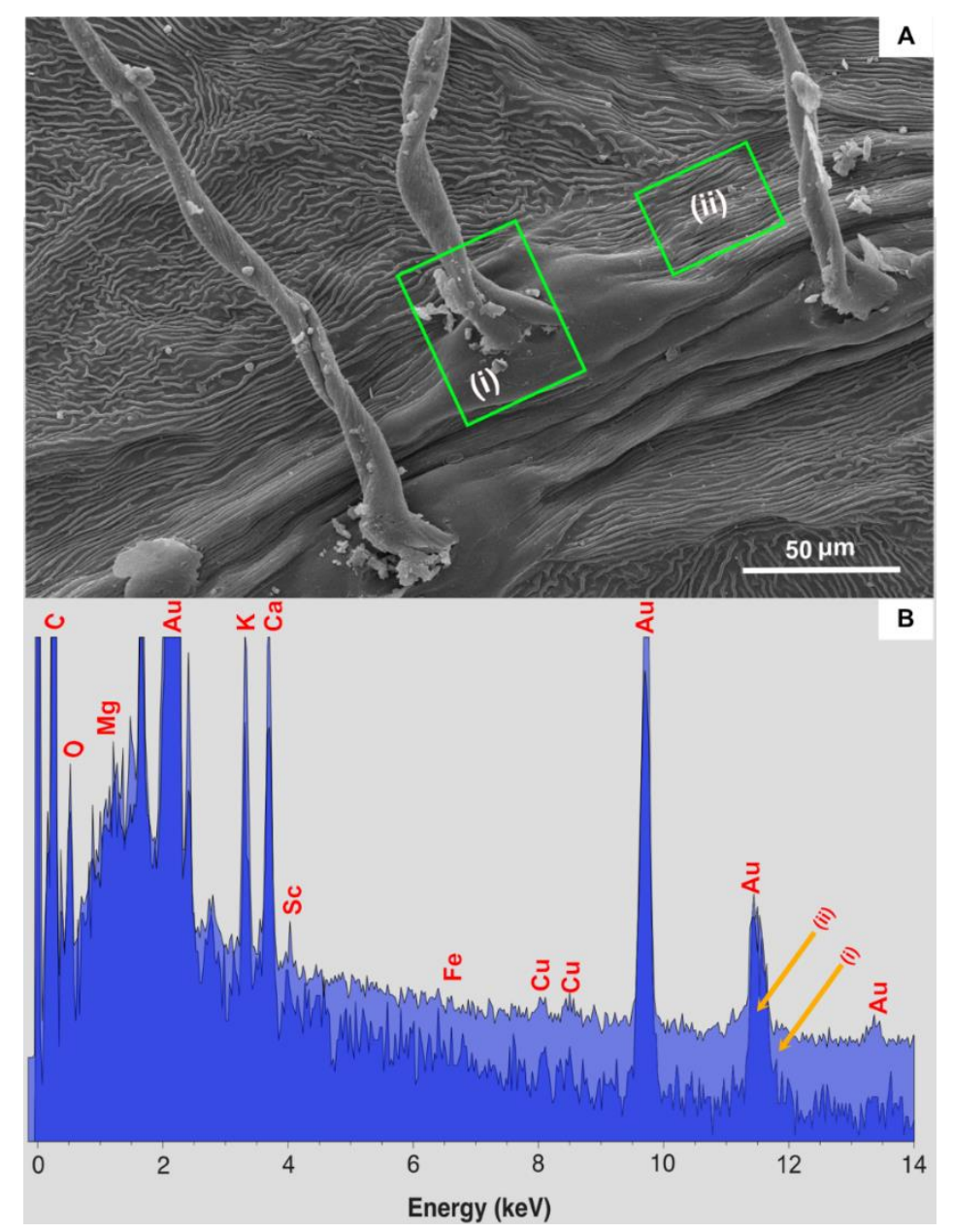

397

398 Fig. 5 (A) Scanning electron micrograph of the adaxial surface of the pre-exposure silver birch 399 leaf, and (B) EDAX spectra for the leaf-deposited PM in sub-areas (i) and (ii) of image (A). 400 (Note that the sample was gold-coated).

401

402 i.e., stomata occur only on the underside of the leaves. SEM-EDAX analysis of the silver birch 403 leaf surfaces shows very low content of transition metal-bearing PM on the pre-exposure leaves 404 


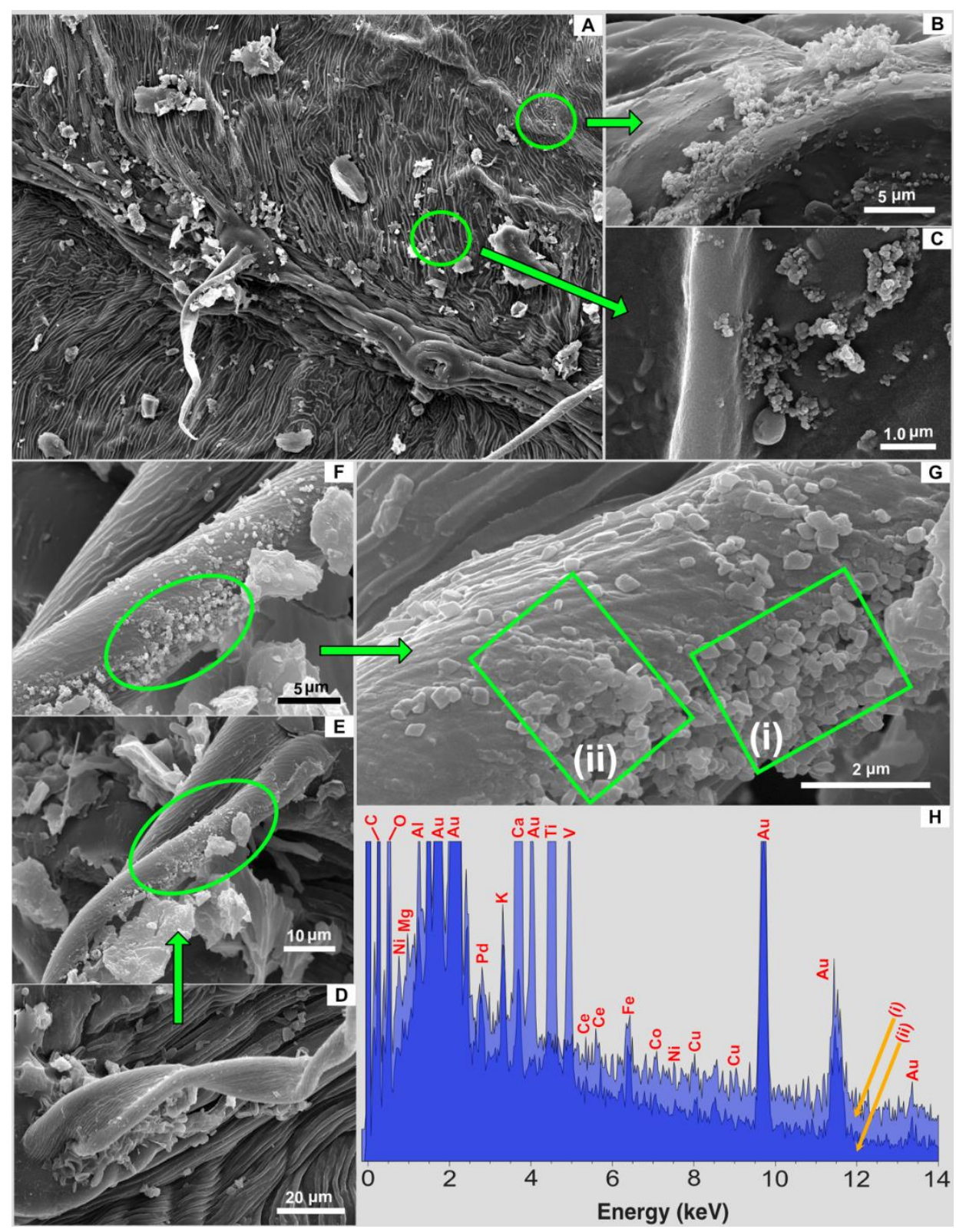

406 Fig. $6(\mathrm{~A})-(\mathrm{G})$ : Scanning electron micrographs of the post-exposure silver birch leaves, and

407 (H) EDAX spectra of the deposited particles shown in areas (i) and (ii) in micrograph (G).

408

409 (Fig. 5). In contrast, post-exposure, the silver birch surface displays an abundance of particles

410 within the PM2.5 range (Fig. 6), displaying a range of particle sizes and morphologies, including

411 aggregated rounded chains of particles (Fig. 5C and Fig. S7), and discrete geometric particles

412 (Fig. 6G). The post-exposure accumulation of UFPs within the micro-indentations of the rough 
413 leaf surface, and along and around the leaf hairs is noteworthy. These locations appear to be

414 'hot spots' for capturing UFPs; and may also act as gateways for UFP access to the leaf interior

415 structure.

416 Prior to exposure, the major PM elemental contributions comprise $\mathrm{C}, \mathrm{O}, \mathrm{Mg}, \mathrm{K}$, and $\mathrm{Ca}$

417 (Fig. 5B). In contrast, the post-exposure birch leaves display higher concentrations of UFPs

418 containing a much broader elemental range; specifically, the presence of $\mathrm{Ni}, \mathrm{Fe}, \mathrm{Ti}, \mathrm{V}, \mathrm{Ce}$,

419 Al, Pd, Cu and Co (Fig. 6H).

420

421

4. Discussion

422

These wind-tunnel experiments show that some plant species (silver birch, yew, elder, maple and ash) display UFP removal efficiencies as high as $\sim 60$ to $80 \%$, demonstrating that 424 selected plant species can act as effective UFP 'sinks' in the urban environment. Similar 425 magnitudes of PM removal have been reported in real-world contexts for silver birch (for $\mathrm{PM}_{1}$, 426 Maher et al. ${ }^{12}$ ), and mixed woodland in Birmingham, U.K. (for PM estimated at $0.7 \mu \mathrm{m}$, Fowler 427 et $\left.\mathrm{al}^{52}\right)$.

428 Silver birch displayed both peak UFP removal values $(\sim 80 \%)$ and peak removal of 429 particles $<30 \mathrm{~nm}$. It continued to accumulate the finest magnetic particles $(<\sim 20 \mathrm{~nm})$ for 20 430 mins. of exposure, and then accumulated slightly larger and/or agglomerated PM $(\sim 70 \mathrm{~nm})$

431 through to the end of the experiment. It is thus the most efficient of our sampled species in 432 removing diesel exhaust UFPs; followed by yew and elder. Some of the sampled species (e.g. 
ash, cherry) display magnetic evidence of both particle deposition and re-suspension through

434 the time sequence of exposure.

Although nettle and hawthorn appear to be the least efficient plant species, their preexposure magnetic particle loading was higher than the other sampled species. This suggests

437 they may have been 'pre-loaded' with airborne PM, and effectively at or close to a dynamic equilibrium between the rates of particle deposition and loss by re-suspension. In the real world, leaves can continue to accumulate particles (rather than attain equilibrium with ambient PM concentrations) through rainfall wash-off ${ }^{39}$ and entry of PM into the leaf structure via stomata and/or wax cuticle overgrowth ${ }^{61}$.

Leaf surface characteristics and size appear critical regarding PM deposition. Particles are more readily deposited on smaller leaves, with shorter petioles, surface roughness, especially 444 in the form of leaf trichomes, and/or mucilage ${ }^{12,36,38-39,62-64}$. Phoretic effects, in response to 445 gradients in turbulence ${ }^{65}$ ), chemical and/or electric potential ${ }^{66}$, may enhance UFP deposition 446 along leaf hairs.

447 Here, we also found that when the diesel exhaust passed through some of the sampled 448 species, the geomean diameter increased downwind of the vegetation, showing that these plants 449 (silver birch, yew, maple) removed more of the smallest UFPs, possibly of greatest potential 450 hazard to human health.

For our most efficient species, silver birch, many of the UFPs deposited on the postexposure leaves were rich in transition metals, including $\mathrm{Mn}, \mathrm{Ni}, \mathrm{Fe}, \mathrm{Al}, \mathrm{Cr}, \mathrm{V}, \mathrm{Ti}$ and $\mathrm{Cu}$, together with the anti-knock and catalytic converter metals, Ce and Pd. Most of the magnetic 
remanence-capable particles deposited on the post-exposure silver birch leaves were $<100 \mathrm{~nm}$.

455 Nanoparticles of this size can penetrate the body very efficiently ${ }^{2}$, even bypassing the bloodbrain barrier via the olfactory bulb $b^{4-5}$. Similarly, Maher et al. ${ }^{5,12}$ found that many particles deposited on the leaves of silver birches installed at a busy roadside (Lancaster, U.K.) were < $200 \mathrm{~nm}$, exhibited spherical or semi-spherical morphologies, and were Fe-rich. Such Fe-rich particles, abundant and typical of condensation droplets released from high-temperature combustion and frictional (brakewear) processes, are likely to contribute much of the measured magnetic remanence of the plant leaves. Particles rich in transition metals might cause oxidative stress by direct generation of reactive oxygen species not only in lung and cardiovascular cells but also in the brain ${ }^{5}$. Oxidative brain damage is a characteristic of most types of neurodegenerative disease, including Alzheimer's and Parkinson's disease.

All of the data reported here are consistent with the efficient interception and capture of vehicle-derived UFPs by plant leaves, rather than airflow impedance or perturbation, or physical screening effects and "fumigation" of the upwind zone. (In marked contrast, similar experiments on juniper indicate 'blocking' of airflow, and resultant enhancement of upwind PNCs).

Given the health impacts of exposure to traffic-derived PM, it is essential to understand, 471 and optimise, the mitigation potential of roadside vegetation, in order to guide policy 472 appropriately. In the UK, for instance, even reducing the annual average concentration of $\mathrm{PM}_{2.5}$ 473 by only $1 \mu \mathrm{g} / \mathrm{m}^{3}$ would result in a saving of $\sim 3.6$ million life years, equivalent to an increase in 474 life expectancy of 20 days in people born in $2008^{67}$. It is thus timely to improve and update the 
475

476

477

478

479

480

481

482

483

484

485

486

487

488

489

490

491

492

493

494

available data and information regarding PM removal rates by leaf deposition, in order to optimise selection and design of new roadside planting.

Under-estimation by most CFD modelling studies of the potential for substantial PM removal by designed vegetation has negative impacts on policy and potential mitigation. Adoption of realistic, species-specific particle deposition velocities (i.e. up to $\sim 50$ times higher than the values of $0.1,0.2$ and $0.64 \mathrm{~cm} \mathrm{~s}^{-1}$ commonly employed for $\mathrm{PM}_{2.5}$ ) and an appropriate, microscale approach, at road user-relevant heights ${ }^{35}$, are both essential.

In summary, these data indicate that selected plant species can remove by surface deposition substantial amounts $(>50 \%)$ of ultrafine exhaust-derived PM, and of the heavy metals contained within the high particle number concentrations of this PM fraction. Fast, nondestructive magnetic measurements provide an effective indicator of leaf particle deposition. Scanning electron microscopy can identify the major micro-sites associated with greatest particle accumulation. Hence, roadside planting of carefully-selected and managed plant species can effectively mitigate exposure of road users and adjacent residents (especially vulnerable groups like school children) to UFP pollution near major roads. Careful testing and selection of the most efficient species can readily improve air quality.

\section{Acknowledgements}

We are grateful for financial support from Natural Science Basic Research Plan in Shaanxi Province of China (2017JQ4014) and the Research Program of Ministry of Housing and UrbanRural Development of the People's Republic of China (2018-K2-006). We also are grateful to 

and the diesel vehicle.

497

Supporting Information Available: 26 pages, 7 figures and 4 tables. This material is available free of charge via the Internet at http://pubs.acs.org.

\section{References}

1. Liu, J. Y.; Hsiao, T. C.; Lee, K. Y.; Chuang, H. C.; Cheng, T. J.; Chuang, K. J. Association of ultrafine particles with cardiopulmonary health among adult subjects in the urban areas of northern Taiwan. Sci. Total Environ. 2018, 627: 211-215.

2. Miller, M. R.; Raftis, J. B.; Langrish, J. P.; McLean, S. G.; Samutrtai, P.; Connell, S. P.; Inhaled nanoparticles accumulate at sites of vascular disease. ACS nano. 2017, 11(5): $4542-4552$.

3. Stone, V.; Miller, M. R.; Clift, M. J. D.; Elder, A.; Mills, N. L.; Møller, P.; Schins, R. P. F.; Vogel, U.; Kreyling, W. G.; Jensen, K. A.; Kuhlbusch, T. A. J.; Schwarze, P. E.; Hoet, P.; Pietroiusti, A.; Vizcaya-Ruiz, A. D.; Baeza-Squiban, A.; Teixeira, J. P.; Tran, C. L.; 

10.1289/EHP424

4. Oberdörster, G.; Sharp, Z.; Atudorei, V.; Elder, A.; Gelein, R.; Kreyling, W.; Cox, C. Translocation of inhaled ultrafine particles to the brain. Inhal. Toxicol. 2004, 16(6-7): 437-445.

5. Maher, B. A.; Ahmed, I. A. M.; Karloukovski, V.; MacLaren, D. A.; Foulds, P. G.; Allsop, D.; Mann, D. M. A.; Torres-Jardón, R.; Calderon-Garduenas, L. Magnetite pollution nanoparticles in the human brain. P Natl. Acad. Sci. USA. 2016, 113(39): 10797-10801.

6. Bakand, S.; Hayes, A.; Dechsakulthorn, F. Nanoparticles: a review of particle toxicology following inhalation exposure. Inhal. Toxicol. 2012, 24(2): 125-135.

7. Donaldson, K.; Stone, V.; Seaton, A.; MacNee, W. Ambient particle inhalation and the cardiovascular system: potential mechanisms. Environ. Health Perspect. 2001, 109(4): $523-527$.

8. Karlsson, H. L.; Gustafsson, J.; Cronholm, P.; Möller, L. Size-dependent toxicity of metal oxide particles - a comparison between nano-and micrometer size. Toxicol. Lett. 2009, 188(2): 112-118.

9. Rückerl, R.; Schneider, A.; Breitner, S.; Cyrys, J.; Peters, A. Health effects of particulate air pollution: a review of epidemiological evidence. Inhal. Toxicol. 2011, 23(10): 555592. 
11. Shi, J. P.; Harrison, R. M.; Brear, F. Particle size distribution from a modern heavy duty diesel engine. Sci. Total Environ. 1999, 235(1-3): 305-317.

12. Maher, B. A.; Ahmed, I. A. M.; Davison, B.; Karloukovski, V.; Clarke, R. Impact of roadside tree lines on indoor concentrations of traffic derived particulate matter. Environ. Sci. Technol. 2013, 47: 13737-13744.

13. Liati, A.; Schreiber, D.; Dimopoulos Eggenschwiler, P.; Arroyo Rojas Dasilva, Y. Metal particle emissions in the exhaust stream of diesel engines: an electron microscope study. Environ. Sci. Technol. 2013, 47(24): 14495-14501.

14. Zhu, Y. F.; Hinds, W. C.; Kin, S.; Sioutas, C. Concentration and size distribution of ultrafine particles near a major highway. Air Waste Manage. Assoc. 2002, 52: 1032-1042.

15. Liati, A.; Pandurangi, S. S.; Boulouchos, K.; Schreiber, D.; Arroyo Rojas Dasilva, Y. Metal nanoparticles in diesel exhaust derived by in-cylinder melting of detached engine fragments. Atmos. Environ. 2015, 101: 34-40.

16. Kukutschová, J.; Moravec, P.; Tomášek, V.; Matějka, V.; Smolík, J.; Schwarz, J.;

17. Mathissen, M.; Scheer, V.; Vogt, R.; Benter, T. Investigation on the potential generation of from low-metallic automotive brakes. Environ. Pollut. 2011, 159(4): 998-1006. road dust from impervious urban surfaces: distribution, identification, and environmental 
implications. Environ. Sci. Nano. 2016, 3(3): 534-544.

559

560

561

562

563

564

565

566

567

568

569

570

571

572

573

574

575

576

577

578

19. Verma, V.; Shafer, M. M.; Schauer, J. J.; Sioutas, C. Contribution of transition metals in the reactive oxygen species activity of PM emissions from retrofitted heavy-duty vehicles. Atmos. Environ. 2010, 44, 5165-5173.

20. Sanderson, P.; Su, S. S.; Chang, I. T. H.; Delgado Saborit, J. M.; Kepaptsoglou, D. M.; Weber, R. J. M.; Harrison, R. M. Characterisation of iron-rich atmospheric submicrometre particles in the roadside environment. Atmos. Environ. 2016, 140: 167-175.

21. Harrison, R. M.; Shi, J. P.; Xi, S. H.; Khan, A.; Mark, D.; Kinnersley, R.; Yin, J. X. Measurement of number, mass and size distribution of particles in the atmosphere. Philos. T. Roy. Soc. A. 2000, 358(1775): 2567-2580.

22. Heal, M. R.; Kumar, P.; Harrison, R. M. Particles, air quality, policy and health. Chem. Soc. Rev. 2012, 41(19): 6606-6630.

23. Robert, M. A.; Kleeman, M. J.; Jakober, C. A. Size and composition distributions of particulate matter emissions: Part 2-Heavy-duty diesel vehicles. J. Air Waste Manage. Assoc. 2007, 57(12): 1429-1438.

24. Robert, M. A.; VanBergen, S.; Kleeman, M. J.; Jakober, C. A. Size and composition distributions of particulate matter emissions: Part 1-Light-duty gasoline vehicles. J. Air Waste Manage. Assoc. 2007, 57(12): 1414-1428.

25. Jayaratne, E. R.; He, C.; Ristovski, Z. D.; Morawska, L.; Johnson, G. R. A comparative investigation of ultrafine particle number and mass emissions from a fleet of road-road diesel and CNG buses. Environ. Sci. Technol. 2008, 42: 6736-6742. 
26. Herner, J. D.; Hu, S. H.; Robertson, W. H.; Huai, T.; Chang, M. C. O.; Rieger, P.; Ayala, A. Effect of advanced aftertreatment for PM and NOx reduction on heavy-duty diesel engine ultrafine particle emissions. Environ. Sci. Technol. 2011, 45(6): 2413-2419.

27. Su, D. S.; Serafino, A.; Müller, J. O.; Jentoft, R. E.; Schlögl, R.; Fiorito, S. Cytotoxicity and inflammatory potential of soot particles of low-emission diesel engines. Environ. Sci. Technol. 2008, 42(5): 1761-1765.

28. Air Quality Expert Group. Impacts of vegetation on urban air pollution. 2018, 1-40. https://uk-https://uk-air.defra.gov.uk/assets/documents/reports/cat09/1807251306 180509_Effects_of_vegetation_on_urban_air_pollution_v12_final.pdf

29. Janhäll, S. Review on urban vegetation and particle air pollution-Deposition and dispersion. Atmos. Environ. 2015, 105: 130-137.

30. Jeanjean, A. P. R.; Monks, P. S.; Leigh, R. J. Modelling the effectiveness of urban trees and grass on $\mathrm{PM}_{2.5}$ reduction via dispersion and deposition at a city scale. Atmos. Environ. 2016, 147: 1-10.

31. Jeanjean, A. P. R.; Buccolieri, R.; Eddy, J.; Monks, P. S.; Leigh, R. J. Air quality affected by trees in real street canyons: The case of Marylebone neighbourhood in central London. Urban For. Urban Green. 2017, 22: 41-53.

32. Nowak, D. J.; Hirabayashi, S.; Bodine, A.; Hoehn, R. Modeled PM2.5 removal by trees in ten US cities and associated health effects. Environ. Pollut. 2013, 178: 395-402.

33. Vos, P. E. J.; Maiheu, B.; Vankerkom, J.; Janssen, S. Improving local air quality in cities: to tree or not to tree? Environ. Pollut. 2013, 183: 113-122. 
34. Abhijith, K. V.; Kumar, P.; Gallagher, J.; MaNabola, A.; Baldauf, R.; Pilla, F.; Broderick,

601 B.; Di Sabatino, S.; Pulvirenti, B. Air pollution abatement performances of green

602 infrastructure in open road and built-up street canyon environments-A review. Atmos.

$603 \quad$ Environ. 2017, 162: 71-86.

604 35. Santiago, J. L.; Martilli, A.; Martin, F. On dry deposition modelling of atmospheric

605 pollutants on vegetation at the microscale: Application to the impact of street vegetation

606 on air quality. Bound.-Layer Meteor. 2017, 162(3): 451-474.

607 36. Burkhardt, J.; Peters, K.; Crossley, A. The presence of structural surface waxes on

608 coniferous needles affects the pattern of dry deposition of fine particles. J. Exp. Bot.

$609 \quad$ 1995, 46(7): 823-831.

610 37. Beckett, K. P.; Freer-Smith, P. H.; Taylor, G. Particulate pollution capture by urban trees:

611 effect of species and windspeed. Glob. Change Biol. 2000, 6(8): 995-1003.

612 38. Thönnessen, M. Elementdynamik in fassadenbegrünendemWilden Wein (Parthenocissus

613 tricuspidata). Nährelemente, Anorganische Schadstoffe, Platin-Gruppen-Elemente,

$614 \quad$ Filterleistung, Immissionshistorische Aspekte, Methodische Neu-

615 undWeiterentwicklungen. - Kölner Geographische Arbeiten, Heft 78, Geographisches

616 Institut, Universität Köln 2002; pp 103.

617 39. Mitchell, R.; Maher, B. A.; Kinnersley, R. Rates of particulate matter pollution deposition

618 onto leaf surfaces: temporal and inter-species magnetic analyses. Environ. Pollut. 2010,

$619 \quad 158: 1472-1478$.

620 40. Weber, F.; Kowarik, I.; Säumel, I. Herbaceous plants as filters: Immobilization of 
particulates along urban street corridors. Environ. Pollut. 2014, 186: 234-240.

622

623

624

625

626

627

628

629

630

631

632

633

634

635

636

637

638

639

640

641

41. Airborne particulate matter in the United Kingdom; Third report to the Department of the Environment; Quality of Urban Air Review Group (QUARG); HMSO, London, 1996; http://worldcat.org/isbn/0952077132.

42. Gallagher, M. W.; Beswick, K. M.; Duyzer, J.; Westrate, H.; Choularton, T. W.; Hummelshøj, P. Measurements of aerosol fluxes to Speulder forest using a micrometeorological technique. Atmos. Environ. 1997, 31(3): 359-373.

43. Freer-Smith, P. H.; Beckett, K. P.; Taylor, G. Deposition velocities to Sorbus aria, Acer campestre, Populus deltoides $\times$ trichocarpa 'Beaupré', Pinus nigra and $\times$ Cupressocyparis leylandii for coarse, fine and ultra-fine particles in the urban environment. Environ. Pollut. 2005, 133(1): 157-167.

44. Pugh, T. A. M.; Mackenzie, A. R.; Whyatt, J. D.; Hewitt, C. N. Effectiveness of green infrastructure for improvement of air quality in urban street canyons. Environ. Sci. Technol. 2012, 46(14): 7692-7699.

45. Nowak, D. J.; Crane, D. E.; Stevens, J. C. Air pollution removal by urban trees and shrubs in the United States. Urban For. Urban Green. 2006, 4(3): 115-123.

46. Litschke, T.; Kuttler, W. On the reduction of urban particle concentration by vegetation-a review. Meteorol. Z. 2008, 17(3): 229-240.

47. Jin, S. J.; Guo, J. K.; Wheeler, S.; Kan, L. Y.; Che, S. Q. Evaluation of impacts of trees on $\mathrm{PM}_{2.5}$ dispersion in urban streets. Atmos. Environ. 2014, 99: 277-287.

48. Bonn, B.; von Schneidemesser, E.; Butler, T.; Churkina, G.; Ehlers, C.; Grote, R.; Klemp, 
D.; Nothard, R.; Schäfer, K.; von Stülpnagel, A.; Kerschbaumer, A.; Yousefpour, R.;

643 Fountoukis, C.; Lawrence, M. G. Impact of vegetative emissions on urban ozone and

644 biogenic secondary organic aerosol: Box model study for Berlin, Germany. J. Clean Prod. 645 2018, 176: $827-841$.

646 49. Calfapietra, C.; Fares, S.; Manes, F.; Morani, A.; Sgrigna, G.; Loreto, F. Role of Biogenic 647 Volatile Organic Compounds (BVOC) emitted by urban trees on ozone concentration in 648 cities: A review. Environ. Pollut. 2013, 183: 71-80.

649 50. Hoffmann, T.; Odum, J. R.; Bowman, F.; Atmospheric, D. C. J. O. Formation of organic 650 aerosols from the oxidation of biogenic hydrocarbons. J. Atmos. Chem. 1997, 26, 189-222.

51. Matzka, J.; Maher, B. A. Magnetic biomonitoring of roadside tree leaves: identification of spatial and temporal variations in vehicle-derived particulates. Atmos. Environ. 1999, 31: 4565-4569.

52. Fowler, D.; Skiba, U.; Nemitz, E.; Choubedar, F.; Branford, D.; Donovan, R.; Rowland, P. Measuring aerosol and heavy metal deposition on urban woodland and grass using inventories of ${ }^{210} \mathrm{~Pb}$ and metal concentrations in soil. Water Air Soil Pollut. Focus. 2004, 4: 483-499.

53. Baldauf, R.; Thoma, E.; Khlystov, A.; Isakov, V.; Bowker, G.; Long, T.; Snow, R. Impacts of noise barriers on near-road air quality. Atmos. Environ. 2008, 42(32): 7502-7507. nanoparticles and pedestrians exposure under varying wind conditions. Atmos. Environ. 2014, 90(90): 113-124. 
663

664

665

666

667

668

669

670

671

672

673

674

675

676

677

678

679

680

681

682

683

55. Lin, M. Y.; Hagler, G.; Baldauf, R.; Isakov, V.; Lin, H. Y.; Khlystov, A. The effects of vegetation barriers on near-road ultrafine particle number and carbon monoxide concentrations. Sci. Total Environ. 2016, 553: 372-379.

56. Lin, M. Y.; Khlystov, A. Investigation of ultrafine particle deposition to vegetation branches in a wind tunnel. Aerosol Sci. Technol. 2011, 46: 465-472.

57. Hwang, H. J.; Yook, S. J.; Ahn, K. H. Experimental investigation of submicron and ultrafine soot particle removal by tree leaves. Atmos. Environ. 2011, 45: 6987-6994.

58. Davison, B.; Whyatt, D.; Boardman, C. Aerosol evolution from a busy road in North-west England. Meteorogische Zeitschrift. 2008, 18(1): 55-60.

59. Maher, B. A. Magnetic properties of some synthetic sub-micro magnetites. Geophys. J. Int. 1988, 94: 83-96.

60. Maher, B. A.; Karloukovski, V. V.; Mutch, T. J. High-field remanence properties of synthetic and natural submicrometre haematites and goethites: significance for environmental contexts. Earth Planet. Sci. Lett. 2004, 226(3-4): 491-505.

61. Lehndorff, E.; Urbat, M.; Schwark, L. Accumulation histories of magnetic particles on pine needles as function of air quality. Atmos. Environ. 2006, 40(36): 7082-7096.

62. Wang, H. X.; Shi, H.; Li, Y. Y.; Zhang, J. Seasonal variations in leaf capturing of particulate matter, surface wettability and micromorphology in urban tree species. Front. Env. Sci. Eng. 2013, 7(4): 579-588.

63. Liu, J. Q.; Cao, Z. G.; Zou, S. Y.; Liu, H. H.; Hai, X.; Wang, S. H.; Duan, J.; Xi, B. Y.; Yan, G. X.; Zhang, S. W.; Jia, Z. K. An investigation of the leaf retention capacity, 
684 efficiency and mechanism for atmospheric particulate matter of five greening tree species 685 in Beijing, China. Sci. Total Environ. 2018, 616-617: 417-426.

686 64. Weerakkody, U.; Dover, J. W.; Mitchell, P.; Reiling, K. Evaluating the impact of 687 individual leaf traits on atmospheric particulate matter accumulation using natural and 688 synthetic leaves. Urban For. Urban Green. 2018, 30: 98-107.

689 65. Hicks, B. B.; Saylor, R. D.; Baker, B. D. Dry deposition of particles to canopies-A look 690 back and the road forward. J. Geophys. Res.-Atmos. 2016, 121(24): 14691-14707.

691 66. Moran, J. L.; Posner, J. D. Phoretic self-propulsion. Annu. Rev. Fluid Mech. 2017, 49: $692 \quad 511-540$.

693 67. The mortality effects of long-term exposure to particulate air pollution in the United 694 Kingdom; Committee on the Medical Effects of Air Pollutants, Department of Health, 695 London, UK, 2010; http://comeap.org.uk/documents/reports/128-the-mortality-effects-of696 long-term-exposure-toparticulate-air-pollution-in-the-uk.html.

697

698 
699 TOC

700

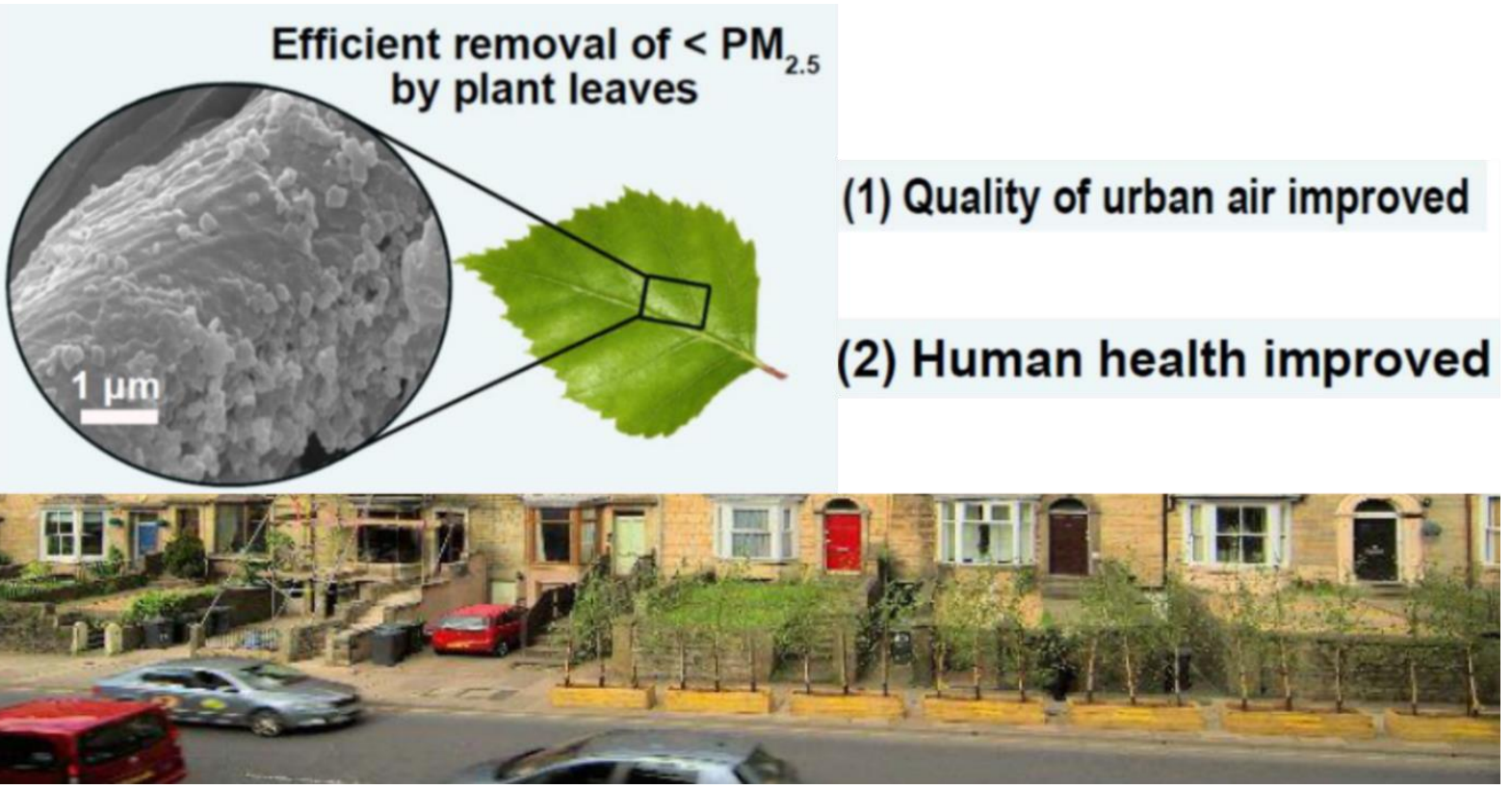

